\title{
Portrait representation of postmenopausal women's experiences of living with urinary incontinence
}

\begin{abstract}
This study explored the meaning of the experiences of community-dwelling postmenopausal women who were born and grew up in a Muslim country when drawing a picture about their lived experiences of urinary incontinence. Hermeneutic phenomenology underpinned the study's interpretive research approach. In-depth, semistructured interviews were conducted in two sessions with nine postmenopausal women. The participants were asked to draw a picture about their lived experiences of urinary incontinence in a self-portrait. Three themes emerged to illuminate the meaning of urinary incontinence, including "disruption of normal functioning," "self-imposed restrictions," and "feeling of despair." Discussion of these themes was presented, and practice and research implications were suggested.
\end{abstract}

Keyword: Lived experience; Self-portrait; Urinary incontinence; Postmenopausal women; Hermeneutic phenomenology 